\title{
Editorial for EAIT issue 1, 2021
}

\author{
Arthur Tatnall ${ }^{1}$
}

Received: 23 December 2020 / Accepted: 23 December 2020 / Published online: 5 January 2021

(C) The Author(s), under exclusive licence to Springer Science+Business Media, LLC part of Springer Nature 2021

Education and Information Technologies (EAIT) is the official journal of the Technical Committee on Education (TC3) of the International Federation for Information Processing (IFIP). It covers the complex relationships between information and communication technologies and education, from the micro of specific applications or instances of use in classrooms to macro concerns of national policies and major projects; from classes of pre-schoolers to adults in tertiary institutions; from teachers and administrators, to researchers and designers; from institutions to open, distance and lifelong learning. The journal's breadth of coverage allows EAIT to examine fundamental issues at all levels, discuss specific instances and cases, draw inference and probe theory. This journal is embedded in the research and practice of professionals.

We are very pleased to announce is that in addition to other indexes, EAIT has recently been accepted into the Social Science Citation Index (SSCI) in the category 'Education \& Educational Research'. The Social Sciences Citation Index is a part of the Web of Science and is a multidisciplinary index to the journal literature of the social sciences.

To begin this issue is an article from Kseniia Vilkova and Irina Shcheglova (Institute of Education, National Research University Higher School of Economics, Moscow, Russia) titled: Deconstructing self-regulated learning in MOOCs: In search of helpseeking mechanisms. Researchers see self-regulated learning (SRL) as a fundamental skill for succeeding in massive open online courses (MOOCs), but there is insufficient evidence of adequate functioning of SRL dimensions such as environment structuring, goal setting, time management, help-seeking, task strategies, and self-evaluation in the MOOC environment. This study fills the gap in understanding the structure of SRL skills utilising the Online Self-Regulated Learning Questionnaire (OSLQ). Their results show that the original six-factor hierarchical model does not fit the data adequately as evidence implies that the dimension 'help-seeking' is not effective in the MOOC environment. A redefined five-factor hierarchical model of the OSLQ is suggested.

Effects of the blended learning model on preservice teachers' academic achievements and twenty-first century skills is an article by Cihad Şentürk (Karamanoğlu

Arthur Tatnall

Arthur.Tatnall@vu.edu.au

1 Victoria University, Melbourne, Australia 
Mehmetbey University, Karaman, Turkey). In their study, a semi-experimental research design with experimental and control groups was employed. Data collection tools were an academic achievement test and "multidimensional twenty-first century skills scale". Analysis revealed that there was a significant difference across the two groups' academic achievement and twenty-first century skills in favour of the experimental group and an analysis of the retention test administered four weeks later again a showed significant difference in favour of the experimental group.

Evren Eryilmaz (California State University Sacramento, USA), Brian Thoms (California State University Channel Islands, Camarillo, USA), Zafor Ahmed (University of Houston-Downtown, USA) and Kuo-Hao Lee (Bloomsburg University, USA) then present: Effects of recommendations on message quality and community formation in online conversations. This study draws on literature from group cognition, knowledge building discourse and learning analytics, the calculated message quasi-quality index (QQI) scores based on message lexical complexity and topicrelated keyword usage by participants in explaining their ideas. They also visualized network structures via sociograms and hierarchically cluster participants to identify subgroups and found that recommendations helped participants write more messages that compared alternative viewpoints and refined preliminary ideas with higher QQI scores.

Learning analytics have offered promising capabilities and opportunities to many aspects of academic research and higher education studies, and in $\boldsymbol{A}$ two-phase machine learning approach for predicting student outcomes Omiros Iatrellis, Ilias K. Savvas, Panos Fitsilis and Vassilis C. Gerogiannis (University of Thessaly, Larissa, Greece) discuss this. Data-driven insights can significantly contribute to provide solutions for curbing costs and improving education quality and this paper adopts a two-phase machine learning approach, which utilizes both unsupervised and supervised learning techniques for predicting outcomes of students following Higher Education programs of studies. The developed models discussed are claimed to produce predictions with relatively high accuracy. The paper discusses the potential usefulness of the clustering-aided approach for learning analytics in Higher Education.

eLearning technology and the advancement of practical constructivist pedagogies: Illustrations from classroom observations was contributed by: Paul L.C. LAM, Hilary K.Y. NG and Alan H.H. TSE (The Chinese University of Hong Kong, Sha Tin), Ming $\mathrm{Lu}$ (University of Cologne, Germany, and The Chinese University of Hong Kong, Sha Tin) and Bernardo Y. W. WONG (The Chinese University of Hong Kong, Sha Tin). With the advancement of technology, eLearning is increasingly adopted as an instructional method in a wide range of educational settings and has opened-up new possibilities in teaching and learning practices, but there is insufficient empirical evidence to illustrate how eLearning benefits teaching and learning practice in its real-world applications. Their study illustrates how eLearning technology can advance five constructivist pedagogies: 1) active learning, 2) student-centred learning, 3) peer learning, 4) personalized learning, and 5) differentiated learning. It discusses how the interactive, self-paced, repetitious, and customizable features of eLearning systems facilitate the implementation of these five constructivist pedagogies.

Integration of fuzzy logic with Metaheuristics for education center site selection describes research by: Aastha Agrawal, Anjali Agarwal and Priti Bansal (Netaji Subhas Institute of Technology, Dwarka, New Delhi, India) who point out that education is one 
of the most vital sectors of any nation's development. Site selection for Education Centers (EC) like schools, colleges, and coaching centres can be a very complex process involving parameters like population, literacy rate and property cost that have to be considered. This paper presents two integrated approaches, Fuzzy Genetic Algorithm for EC site selection (FGA-ECSS) and Fuzzy Binary Particle Swarm Optimization for EC site selection (FBPSO-ECSS) for choosing sites optimally. To evaluate the effectiveness of the two approaches, FGA-ECSS and FBPSO-ECSS have been compared with each other as well as with Genetic Algorithm and Binary Particle Swarm Optimization.

Integrating ICT into schools in Sub-Saharan Africa: from teachers' capacity building to classroom implementation describes a study where teachers from Kenya, Tanzania, Uganda, Ethiopia, Ghana and Nigeria were involved in an instructional digital professional development programme targeted at building their capacity to embed ICT into school organizational and curriculum practice. This study, by Douglas Darko Agyei (University of Cape Coast, Ghana) sought to evaluate the impact of the ICT- instructional professional development program in relation to the quality and the extent of the teachers' transfer of the program's ideas from capacity building to classroom instructional practices. Implications for effective professional development in integrating ICT into school organization and curriculum practices that have sustainable impact on teaching and learning particularly in Sub-Saharan regions and similar contexts are discussed.

Silvia Gaftandzhieva, Mariya Docheva and Rositsa Doneva (University of Plovdiv "Paisii Hilendarski", Bulgaria) next offer: A comprehensive approach to learning analytics in Bulgarian school education. They point out that many educational institutions use a large number of information systems to automate their activities for different stakeholders' groups - learning management systems, student diary, library system, digital repositories and management systems. The paper presents a comprehensive approach to Learning Analytics in the field of Secondary Education from the perspective of all different stakeholders, which aims to improve methods of approaching and analysing learning data.

Increasing pre-service teachers' multicultural sensitivity through online learning by Shelanee Theresa P. Ruales (Laboratory for Education and Society, Leuven, Belgium and Mindanao State University - Iligan Institute of Technology, Iligan City, Philippines), Wim Van Petegem (Faculty of Engineering Technology, KU Leuven, Belgium), Josefina M. Tabudlong (Mindanao State University, Iligan City, Philippines) and Orhan Agirdag (Laboratory for Education and Society, Leuven, Belgium and University of Amsterdam, The Netherlands) notes that the role of pre-service teacher education is crucial in culturally diverse contexts where conflict exists. Their study examined whether pre-service teachers' multicultural sensitivity can be increased through a Transformative Learning Theory-based online course. The findings of this study can inform both theory and practice on how multicultural sensitivity can be increased and how Transformative Learning Theory can be applied in online course design.

Understanding digitalization and educational change in school by means of activity theory and the levels of learning concept by Fanny Pettersson (Umeå University, Beteendevetarhuset Hus, Sweden) points out that digitalization processes are often limited to implementation of digital technologies without pedagogical and 
organizational change. This study argues a broader perspective on the concept of digitalization, viewing it as a process involving change and transformation in different stages and several organizational levels. Based on cultural-historical activity theory and the concept of levels of learning, it elaborates on the concept of digitalization as well as how schools are dealing with digital and educational change. In its analysis, the paper indicates that the object of digitalization harbors an idea that influences how digitalization is planned for and enacted within the school organization.

Student performance modelling is one of the challenging and popular research topics in educational data mining (EDM) and Student performance analysis and prediction in classroom learning: A review of educational data mining studies by Anupam Khan and Soumya K. Ghosh (Indian Institute of Technology Kharagpur, West Bengal, India) addresses this topic. In their paper they present a systematic review of EDM studies on student performance in classroom learning, focusing on identifying the predictors, methods used for such identification, time and aim of prediction. The paper presents a review of studies in which the meta-analysis indicates that the researchers achieve significant prediction efficiency during the tenure of the course. However, performance prediction before course commencement needs special attention.

Charles Buabeng-Andoh (University of Education, Winneba, Ghana) then presents: Exploring University students' intention to use mobile learning: A research model approach. The author notes that although a substantial number of learning organizations have embraced tools to boost mobile learning, research into the determinants of its acceptance is still in its infancy. This study empirically explored the validity of the integrated model of the theory of planned behaviour and the technology acceptance model (TAM) in explaining the determinants that drive university students' intentions to use mobile learning technology. The results showed that attitude significantly affects behavioural intention and that perceived usefulness, perceived ease of use, self-efficacy, and subjective norm positively affect attitude. Attitude had the greatest effect on technology usage intention while self-efficacy had the smallest effect.

Virtual Learning Communities (VLCs) rethinking: From negotiation and conflict to prompting and inspiring. Spyros Tzanavaris, Stefanos Nikiforos, Despoina Mouratidis and Katia Lida Kermanidis (Ionian University, Corfu, Greece) point out that research analysis usually focuses on terms of negotiation -argument, conflict, agreement, and disagreement as indications of collaborative learning. The reported research suggests that the latter can also exist in terms of prompting and inspiring and in terms of negotiation. The nature of the dialogues in the reported VLC seems to be a special form of discourse addressing community context, mainly characterized by prompting and inspiring while less of negotiation and conflicts.

M-learning adoption of management students': A case of India by Sadhna Shukla (Gurugram, India) looks at management student's motivation to adopt m-learning and assesses the determinates impacting the behavioural intent of m-learning adoption. A comprehensive research archetype is proposed by integrating two prominent theoretical models, namely UTAUT and UGT. The study outcomes reported that affective need, performance expectancy, effort expectancy, social influence and facilitating conditions positively impacted the student's intent to use m-learning, whereas cognitive need was found to be insignificant in predicting and explicating m-learning adoption. The results of sensitivity analysis revealed that effort expectancy showed the highest normalized importance followed by performance expectancy. 
Next, Reza Ghanbarzadeh (Southern Cross University, Gold Coast, QLD, Australia and Griffith University, QLD, Australia) and Amir Hossein Ghapanchi (Victoria University, Melbourne, VIC, Australia and Griffith University, QLD, Australia) write on: Uncovering educational outcomes deriving from students' acceptance and involvement with $3 D$ virtual worlds. They indicate that Three-Dimensional Virtual World (3DVW) is one of the promising innovations in the field of ICT. This includes user-created content and allow for user-defined purpose and a sense of presence, where users can navigate and manipulate objects within the virtual environment through their avatar. This research examined the educational outcomes of using 3DVW by higher education students and identified factors consequent on students' acceptance of 3D Virtual World: positive learning outcome, satisfaction, engagement, learning style, environment impact, retention, skill development, and connectedness.

Temporality revisited: Dynamicity issues in collaborative digital writing research by Volkmar P. Engerer (University of Copenhagen, Denmark) explores the feature of dynamicity (a composite of temporal and local properties) in research on academic writing assignments. The article traces the ways in which current research typically approaches collaborative digital writing (CDW) and identifies the underlying elements of current and technological inquiry in this field: components of text (the process and products of writing and learning communication), external variables, such as learning orientations and group composition, and an intermediate layer of time management that is related to organizing the assignment. The paper argues for the ideas of sequential concept construction and locally changing sources for the writer at a certain point in the writing.

Analysis of learning behaviour of MOOC users has become a challenge in the Learning Analytics field, which is especially related to video lecture data, since most learners watch the same online lecture videos. Predictive learning analytics using deep learning model in MOOCs' courses videos by Ahmed Ali Mubarak (Shaanxi Normal, Xi'an, University, China and Ibb University, Yemen), Han Cao (Shaanxi Normal University, China) and Salah A.M. Ahmed (Shaanxi Normal University, Xi'an, China) addresses this topic. This paper exploits a temporal sequential classification problem by analysing video clickstream data to predict learner performance by addressing their issues and improving the educational process.

The unified model of task-specific motivation and teachers' motivation to learn about teaching and learning supportive modes of ICT use describes research by Cornelis J. de Brabander (Leiden University, Open University of The Netherlands and Query Informatisering, Voorhout, The Netherlands) and Folke J. Glastra (Leiden University, The Netherlands). According to the Unified Model of Task-specific Motivation (UMTM), readiness for action is driven by feelings of activities and thoughts about the value of consequences of activities, which can be both positive and negative, and which in turn are influenced by aspects of autonomy and competence, by social relatedness, and by subjective norm. The twofold goal of this study was to test the merits of the model in general, and for ICT integration in education in particular. Although sense of competence was relatively more important for leaning about learning supportive ICT use than for learning about teaching supportive ICT use, teachers' sense of autonomy, a variable that is completely ignored in research on ICT integration, was in general far more important for learning about ICT use than sense of competence.

Cláudia Pinho (University of Beira Interior, Portugal), Mário Franco and Luis Mendes (University of Beira Interior, CEFAGE-UBI Research Center, Portugal) then 
write on Application of innovation diffusion theory to the E-learning process: higher education context. This empirical study aims to identify the factors influencing the use of Moodle as a Learning Management System (LMS) in the academic context. The results obtained showed that the characteristics of Moodle LMS, proposed by Innovation Diffusion Theory and Personal Innovativeness in Information Technology positively influence the use of this tool. These and other implications and suggestions for future research are also presented.

Does behavior simulation based on augmented reality improve moral imagination? Ratna Candra Sari (Universitas Negeri Yogyakarta, Yogyakarta, Indonesia), Mahfud Sholihin (Universitas Gadjah Mada, Yogyakarta, Indonesia), Nurhening Yuniarti (Universitas Negeri Yogyakarta, Yogyakarta, Indonesia), Ida Ayu Purnama (Universitas Pembangunan Nasional Veteran Yogyakarta, Yogyakarta, Indonesia) and Hardika Dwi Hermawan (Universitas Muhammadiyah Surakarta, Indonesia) next write on this topic. They argue that innovative learning techniques are needed to match current expectations to improve business ethics education for the twenty-first century. One of the innovative technologies which is believed to have a big effect on a bachelor's degree is augmented reality (AR) and incorporating AR into a modern education system is expected to produce optimal augmentation in the learning and teaching environment. This study examines the use of AR-based behaviour simulation, as an innovative technique for learning ethics, to improve moral imagination.

Voki is a tool of web 2.0 for students' academic achievement and attitudes towards English courses. Serkan Yeșilbağ and Özgen Korkmaz (Amasya University, Turkey) next present a paper on: The effect of Voki application on students' academic achievements and attitudes towards English course. The study group of this research consists of 5th grade students at a public secondary school in the Merkezefendi district of Denizli province. In the experimental group, the "Party Time" unit was taught via Voki-supported activities while the same unit was taught according to the current curriculum without using Voki in the control group. There was seen to be an increase in the achievement test scores of both groups in the English lesson, but a statistically significant difference was observed in the speaking section of the experimental group.

Investigating the impact of computer-assisted pronunciation teaching (CAPT) on improving intermediate EFL learners' pronunciation ability next comes from Adeleh Jamshidi Saleh and Abbas Pourhosein Gilakjani (Islamic Azad University, Lahijan, Iran). They note that Computer-Assisted Pronunciation Teaching (CAPT) software has been developed to improve learners' pronunciation. It helps learners to study independently, selecting what function to use and how often they utilize it. CAPT systems are regarded as a useful tool for pronunciation training for learners, specifically those who feel uncomfortable having their pronunciation corrected in front of other learners. Based on statistical analyses, it was concluded that CAPT had a significant effect on Iranian intermediate EFL learners' pronunciation.

Transforming universities in interactive digital platform: case of city university of science and information technology is by Muhammad Nauman Habib (City University of Science and Information Technology, Peshawar, Pakistan) \& Waseef Jamal (Institute of Management Sciences, Peshawar, Pakistan), Uzma Khalil and Zunnoorain Khan (City University of Science and Information Technology, Peshawar, Pakistan). Their purpose was to understand the automation of Higher Education Institutes and to evaluate the automated process from the perspective of a developing country. The 
university has a state-of-the-art automated infrastructure, management information system and learning management system (LMS) which facilitates faculty, staff, and administration. The LMS provides an integrated and digital platform to key stakeholders particularly to the teachers and students for sharing course outlines and other materials.

Zehra Yıldırım (Mersin University, Turkey) and Medine Baran (Dicle University, Diyarbakır, Turkey) then propose: A comparative analysis of the effect of physical activity games and digital games on 9th grade students' achievement in physics. The study group was made up of secondary school 9th grade students from three different groups at a public school. The first experimental group were taught using the method of Physical Activity Games, the second using Digital Games and the third was the control group. Their findings showed that instructions utilizing digital games and physical activity games contributed positively to the students' academic achievements.

The following article is by Ozlem Uzumcu (Hasan Kalyoncu University, Gaziantep, Turkey) and Erdal Bay (Gaziantep Islam Science and Technology University, Gaziantep, Turkey) and is titled: The effect of computational thinking skill program design developed according to interest driven creator theory on prospective teachers. Their study aimed to improve computational thinking skills of prospective teachers through a program design which includes contents that prospective teachers could use in daily and professional life and includes computer-aided and robotic activities. It was observed in prospective primary education teachers that their thinking skills such as problem-solving and questioning improved, and that they could apply their acquired knowledge and skills to their daily and professional life.

Teaching and learning processes have not experienced major changes during the last centuries, but eLearning platforms may transform these processes, turning the classroom from a teacher-centred and standardised space into a student-centred, customisable and highly scalable environment say Marco Aurélio de Souza Rodrigues (Escola Superior de Propaganda \& Marketing (ESPM/RJ), Brazil), Paula Chimenti and Antonio Roberto Ramos Nogueira (Federal University of Rio de Janeiro, Brazil) in their article: An exploration of eLearning adoption in the educational ecosystem. These changes impact many different stakeholders such as parents, teachers, universities, software developers and textbook publishers. Using discourse analysis, the study identified ten general constructs that simultaneously influence distinct stakeholders in the Brazilian higher education ecosystem in their intention to adopt eLearning.

Alexander Zabolotskikh (Keysight Technologies Inc., Moscow and Russian Federation and Academy of Engineering of Peoples' Friendship University of Russia (RUDN University), Moscow, Russian Federation), Anna Zabolotskikh, Tatiana Dugina and Daria Tavberidze (Peoples' Friendship University of Russia (RUDN University) argue that undergraduate students fail to objectively self-assess grammar skills of English as a second language but mastering English grammar autonomously can assist. Their article: Creating individual learning paths in the Moodle plugin for undergraduate students to study English grammar aims to describe and assess the plugin "RUDN CourseAssist" that offers undergraduate students individual learning paths in studying English grammar.

A case study on learning basic logical competencies when utilising technologies and real-world objects describes research by Robert Weinhandl, Tony Houghton and Zsolt Lavicza (Johannes Kepler University, Linz, Austria). Today, many technologies 
and real-world objects communicate with each other or partly merge, but this combination of technologies and real-world objects has not yet, to any great extent, found its way into everyday teaching practices in schools. To investigate the possibilities of combining technologies and real-world objects in mathematics classes, they conducted an exploratory educational study. Analysing students' data using the principles of grounded theory demonstrated that (A) using open tasks with multiple solutions, (B) immediate feedback and (C) novelty effects in the learning process, are essential to design mathematics learning environments with combining technologies and realworld objects when learning basic logical operations.

Since the beginning of the technology revolution higher education institutions have been in consistent pursuit of technological adoption through digital transformation techniques say Ali Murad Syed, Shabir Ahmad, Adel Alaraifi and Waleed Rafi (Imam AbdulRahman Bin Faisal University, Dammam, Saudi Arabia). Identification of operational risks impeding the implementation of eLearning in higher education system looks at how the transformation from traditional to eLearning education systems face the challenges of ICT and operational risks. They suggest that operational risks in ICT mainly prevent the efficient utilization of eLearning systems. Their study aimed to measure the impact of these risks in higher education institutions.

Contemplative insight as an opinion conflict and a search for meaning in the context of innovative elements of the revolution industry 4.0 by Stefan Chudy, Pavel Neumeister and Iva Koribska (Palacký University in Olomouc, Czech Republic), Martin Strouhal (Charles University in Prague, Czech Republic) and Denisa Selicka (Constantine the Philosopher University in Nitra, Slovak Republic) aimed to present an insight into the issue of technology and innovation reform with an emphasis on their integration into the social sciences. Using discourse analysis, they reconstructed the basic elements of reforms and their reflections into a theory that changes not only in terms of content and terminology, but mainly in terms of logic and rationalization of new paradigms.

Konstantina Sdravopoulou (University of Cordoba, Spain), Juan Jesús Gutiérrez Castillo (University of Seville, Spain) and Juan Manuel Muñoz González (University of Cordoba, Spain) then offer: Naturalistic approaches applied to AR technology: an evaluation. They point out that there is a significant body of research in "naturalistic designs" of augmented reality (AR), concerning different fields (including medicine, education, and arts), but although naturalistic approaches have the potential to enable new forms of experiencing and experimenting with AR technologies, it remains unclear how they can impact participants' motivation. This study aimed to show how naturalistic approaches can be particularly effective in increasing the usefulness of the three widely recognized types of AR (marker-based AR, market-less AR, and location-based AR). Implications are that naturalistic approaches to AR technology help to foster positive attitudes towards it, to enhance the users' social collaboration, personal development, and skills in the use of AR software.

Christopher Shamburg (New Jersey City University, USA) then offers: Rising waves in informal education: women of colour with educationally oriented podcasts. His research explored how and why women of colour begin and continue educationally oriented podcasts. As the number and reach of podcasts increase, the influence of podcasters as informal educators grows, but there are relatively few women of colour in popular podcasting. The qualitative research described examined the work of ten 
women of colour who produce independent podcasts that cover topics appropriate for adult education and examined their origins and work. Findings indicated that these podcasters are driven by a sense of purpose to give voice in an underserved area and are further motivated by their interactions with their audiences. These women tend to focus on building their own networks and capitalizing on the unique features of podcasting.

The didactic potential of the voice assistant "Alice" for students of a foreign language at a university is by Alisa N. Al-Kaisi, Alla L. Arkhangelskaya and Olga I. Rudenko-Morgun (Peoples' Friendship University of Russia, Moscow, Russia). They note that students learning a new language are aided by use of a voice assistant when practicing speech, as this allows them to intensify their independent studies and master the elementary level of a foreign language. The purpose of the described study was to test the effectiveness of educational interactions between students who are mastering a beginner level of Russian as a foreign language at university with the aid of the Russian voice assistant "Alice". The observation method allowed them to determine five educational functions of "Alice" while studying a foreign language and five scenarios of educational interaction students had with "her" in the process of their independent study.

Understanding the "this" reference in object-oriented programming: Misconceptions, conceptions, and teaching recommendations comes from Ronit Shmallo (Shamoon College of Engineering, Ashdod, Israel) and Noa Ragonis (Beit Berl College, Kfar Saba, Israel) who present research to expose high school and college engineering students understanding of the 'this' reference in object-oriented programming. Conceptualization of 'this' reflects an understanding of objects in general and involves aspects of programming variants and programmers' preferences as well. To examine students' conceptions, perceptions, and misconceptions they developed a diagnostic tool that uses 'this' in various contexts, such as in constructors, as a visible parameter, for calling an overloaded constructor in class, or while transiting a non-static method using 'this' to a static one.

Shah J Miah and Ian Solomonides (Victoria University, Melbourne, Australia) then present: Design requirements of a modern Business Master's degree course: perspectives of industry practitioners. They indicate that contemporary industry practices must be appropriately reflected in designing modern day teaching and learning programmes, but that existing studies are limited to systematic methodologies for accumulating contemporary practice requirements and using that data to inform the design of educational programmes, even though various, local approaches for doing so often exist in higher education institutions. This paper introduces industry practitioner perspectives of contemporary practice need for conceptualisation and design of a new business master's degree programme. The emerged elements are open-sourced tools based general technical knowledge; specific industry certifications or special skills; technology integration knowledge; cross-industry knowledge such as marketing; project management/agility and decision-making utilising appropriate supporting knowledge.

Regression analysis of student academic performance using deep learning is a paper by Sadiq Hussain (Dibrugarh University, Assam, India), Silvia Gaftandzhieva (University of Plovdiv "PaisiiHilendarski”, Bulgaria), Md. Maniruzzaman (Khulna University, Bangladesh), Rositsa Doneva (University of Plovdiv "PaisiiHilendarski", Bulgaria) and Zahraa Fadhil Muhsin (Baghdad University, Iraq). They suggest that 
educational data mining helps educational institutions to perform effectively and efficiently by exploiting data related to all stakeholders. It can help at-risk students, develop recommendation systems and alert students at different levels. Deep learning has gained momentum in various domains especially image processing with a large dataset. They devised a regression model for analysing the academic performance of the students using deep learning. In their research the deep learning model outperformed the linear regression model.

The next paper describes a study to assess the impact of the integration of tablets and a mobile application for fitness development into a PE lesson in primary education, in schools that did not apply a 'one tablet per child' policy on students' intrinsic motivation for the PE lesson. Introducing tablets and a mobile fitness application into primary school physical education was contributed by: Marina Papastergiou, Petros Natsis, Nikolaos Vernadakis and Panagiotis Antoniou (University of Thessaly, Karyes, Greece). Four fifth grade and four sixth grade classes were assigned either to an experimental or a control group. The experimental group used tablets and an ageappropriate, kid-friendly fitness app, whereas the control group did the same fitness program without technology. Students' intrinsic motivation for the PE lesson attended was assessed in both cases through anonymous questionnaires. The experimental group students reported a higher level of interest and enjoyment than the control group students, although students' perceived effort, perceived competence and feeling of pressure did not differ significantly between the two groups.

Marcelo Campo and Analia Amandi (UNICEN National University, Buenos Aires, Argentina and Consejo Nacional de Investigaciones Científicas y Técnicas, Buenos Aires, Argentina) and Julio Cesar Biset (Comisión de Investigaciones Científicas de la Provincia de Buenos Aires, Argentina) then offer: A software architecture perspective about Moodle flexibility for supporting empirical research of teaching theories. They note that Moodle represents a big contribution to the educational world since it provides an evolving platform for Virtual Learning Management Systems that has become a de facto standard for most of the educational institutions around the world. They say that it collects from many global databases a huge amount of information regarding the activities that teachers and students perform during the learning process, making it a natural choice for conducting experimental research by Artificial Intelligence researchers interested in theories for improving learning and teaching. Their research involved development of Middle, a Moodle plug-in able to infer the learning style of each student taking a course using an advanced version of a previously tested Bayesian network model.

The next article by Adit Gupta and Pooja Pathania (MIER College of Education, Jammu, India) is: To study the impact of Google Classroom as a platform of learning and collaboration at the teacher education level. Data analysis revealed that students could access the learning activities easily, they could communicate with other students in their subject electronically, they could decide when they wanted to learn, and they could work at their own pace. Results also showed that the students could regularly access online resources and they had the autonomy to ask their tutor about anything they did not understand. Students experienced a sense of satisfaction and achievement and they felt at ease in working collaboratively with other students.

Learning programming by creating games through the use of structured activities in secondary education in Greece by Eleni Seralidou and Christos Douligeris 
(University of Piraeus, Greece) suggests that effective teaching of the concepts of programming, where critical thinking is an important factor, is not easy in secondary education. They suggest that new teaching approaches, including, game-based learning, may provide a solution due to their inclusion of more fun and diverse activities, but they still lack the active participation of the students in the creation of the material. To help students learn the basics of programming though creating games using a blocktype programming environment, they developed new teaching and learning materials to teach programming principles, like conditionals, loops, and variables, to secondary education students based mainly on a constructivist philosophy.

The moderating effect of social capital on co-regulated learning for MOOC achievement is a paper by Rawad Chaker (Lyon 2 University, France) and Maria Antonietta Impedovo (Aix-Marseille University, Marseille, France). Their aim was to track down elements of self-regulated learning in a massive open online course regarding social capital. It was oriented to explore the relationship between feeling of belonging to an online community and individual and collective regulation of learning. They found that co- regulated and self-regulated learning strategies lead to MOOC achievement, and social capital is only a moderator of co-regulated learning but not for self-regulated learning individual environment control.

Video-based self-reflection among pre-service teachers in Ireland: A qualitative study from Selina McCoy (Economic and Social Research Institute, Ireland and Trinity College Dublin, Ireland) and Aoife M. Lynam (Hibernia College, Dublin, Ireland) investigate how, with increased accessibility to digital video equipment there has been interest in exploring how this might support practice and pedagogy across many education sectors. This paper examines the potential for digital observation within initial teacher education as a tool for engaging pre-service teachers in reflective practice during school placement. The study included pre-service primary teachers with a treatment group completing their compulsory written reflections as normal during school placement but were also provided with Swivl digital technology to record and reflect on their lessons using video footage. A control group completed their traditional written reflections as normal without the use of the digital technology. Analysis showed that digital video footage was supportive in pre-service teachers' weekly self-reflection and in developing self-reflective practice.

Mohamed A. Amasha, Marwa F. Areed, Dalia Khairy and Safaa M. Atawy (Damietta University, Egypt), Salem Alkhalaf (Qassim University, Alrass, Saudi Arabia) and Rania A. Abougalala (Damietta University, Egypt) then offer: Development of a Javabased Mobile application for mathematics learning. The purpose of this study was to determine the effects of a mobile application on student achievement in a primary school mathematics course in Saudi Arabia. Java was used in the development of the application. The data collection instrument was a test in a mathematics course. Findings revealed that mobile applications are more effective than traditional methods for improving student outcomes in mathematics, indicating a need for support for such activities in primary school classes.

Next, Gábor Csapó, Katalin Sebestyén, Mária Csernoch and Kálmán Abari (University of Debrecen, Hungary) present: Case study: Developing long-term knowledge with Sprego. In Hungary, K-12 informatics/computer science education focuses mostly on surface-based methods. This approach can be observed in the teaching of several topics of which they focus on spreadsheet management. In the process of fulfilling the 
requirements of the school curricula and the various tool-centred exams, students become familiar with the software interfaces and how to navigate them, instead of developing computational thinking skills and learning how to approach and solve realworld problems. Their research group focuses on spreadsheeting with an algorithmbuilding and problem-solving method at the centre of the teaching-learning process. They thus developed and introduced the Sprego (Spreadsheet Lego) methodology. Sprego is based on Pólya's four-step concept-based problem-solving approach, and its efficiency has already been proved compared to traditional low-mathability surfaceapproach methods.

Despite extensive proliferation of social media in different domains, higher education academics' use of social media remains unclear say Ritesh Chugh and Robert Grose (CQUniversity, Melbourne, Australia) and Stephanie A. Macht (CQUniversity, Sydney, Australia) in their article: Social media usage by higher education academics: A scoping review of the literature. Theis paper addresses this gap in the literature by providing a scoping review, covering the last five years of extant literature, compiling and analysing previous empirical studies concerning academics' usage of social media, the benefits of social media for academics, and the challenges and barriers that academics face when using or considering using social media. Despite limited use of social media by academics, this provides clear benefits for career development, research, and teaching, including improved communication with various stakeholders, increased opportunities and contacts, and increased student learning and satisfaction.

The effect of E-books on Preservice student teachers' achievement and perceptions in the United Arab Emirates is a paper by Abdurrahman Ghaleb Almekhlafi (United Arab Emirates University, UAE). E-books are replacing textbooks at educational institutions worldwide, but their effectiveness depends on factors such as design, interactivity, richness of content, and students' perceptions of the benefits they gain or think they gain. This study investigated the effect of e-books on learning technological course content and assess to preservice student teachers' perceptions of the usefulness of e-books for their course learning. Results showed that preservice teachers had a significantly more positive attitude towards the usefulness of the interactive e-book version for content learning than towards other versions and reported more advantages and fewer disadvantages of the interactive version compared to the other versions.

Conventional teaching methods like the use of demonstration, lecture and project methods in teaching skilled/trade subjects is still persistent among higher education institutions in Nigeria say Taiwo Olabanji Shodipe and Ifeanyi Benedict Ohanu (University of Nigeria, Nsukka, Enugu State, Nigeria). Their article: Electrical/electronics technology education teacher's attitude, engagement, and disposition towards actual usage of Mobile learning in higher institutions examines this. Their study found that teachers' perceived ease of use had a significant positive link on usage of mobile learning (ML). Their disposition was positively linked with perceived ease of use, their psychological well-being and perceived usefulness, while technical/ technology teachers' training linked negatively with perceived ease of use of ML. The study affirmed that technical teacher education training and psychological well-being influence perceived ease of use and perceived usefulness towards actual usage of mobile learning.

Azucena Hernández-Martín and Marta Martín-del-Pozo (University of Salamanca, Paseo de Canalejas, Salamanca, Spain) and Ana Iglesias-Rodríguez (University of 
Salamanca, Ávila, Spain) then offer the results of a study devoted to the assessment of Spanish pre-adolescents' digital competences between the ages of 11 and 13, in an article titled: Pre-adolescents' digital competences in the area of safety. Does frequency of social media use mean safer and more knowledgeable digital usage? It was based on the implementation of a validated digital competences test designed to cover the five digital competence areas included in the European Digital Competence Framework (DIGCOMP), a common framework of reference on digital competence in Europe. These are: information, communication, content creation, safety and problem solving. This study is focused on the competence area of safety and on its analysis in relation to Spanish pre-adolescents and whether their results regarding this competence area are influenced by how frequently they use social media.

First year students' experience in a Cyber World course - an evaluation describes research by Frank Breitinger (University of New Haven, West Haven, USA and University of Liechtenstein, Vaduz, Liechtenstein), Ryan Tully-Doyle, Kristen Przyborski, Lauren Beck and Ronald S. Harichandran (University of New Haven, West Haven, USA). They point out that although cybersecurity is a major present concern, it is not a required university subject. In response, they developed 'Cyber World' which introduces students to eight highly important cybersecurity topics (primarily taught by non-cybersecurity experts). This article presents the evaluation of the course, comparing the performance of Cyber World students to other Common Course sections that ran in parallel. They concluded that despite the higher workload, students performed equally well.

I. Chien Chen, Christel Rocha-Beverly and Barbara Schneider (Michigan State University, East Lansing, USA) next offer: Alignment of educational aspirations and career plans in high school with Mobile app technology. Init2Winit is a gamified mobile application designed to promote college and career knowledge among adolescents. It offers students multiple opportunities to explore college and career pathways using game tunnels to inform students' understanding of how mis/aligned choices can have varying consequences for their future. Their study examines player performance in the career tunnel, where students attempt to align their educational expectations with chosen career pathways. Results show that students who earned high alignment scores increased their college-going expectations.

No more excuses, learn English for free: Factors affecting L2 learners' intention to use online technology for informal English learning from Shima Balouchi and Arshad Abdul Samad (Universiti Putra Malaysia, Selangor, Malaysia) points out that there is a wealth of research investigating language learners' adoption of digital technology in higher education. This study aimed to identify and test the main factors related to students' informal online English learning (IOEL) that could predict their usage intention. It proposed a model based on the Technology Acceptance Model (TAM) to investigate students' behavioural intention toward IOEL with reference to Malaysian L2 learners. Their results showed that perceived interaction and perceived ease of use were the two main predictors influencing learner's technology acceptance for IOEL.

The effect of online mentoring system through professional learning community with information and communication technology via cloud computing for preservice teachers in Thailand is by Danaisak Karo and Sirirat Petsangsri (King Mongkut's Institute of Technology Ladkrabang, Bangkok, Thailand). The sample 
was pre-service teachers of computer education and was an evaluation of system effectiveness in four components: the ability of function requirement test; the accuracy of function test; the accessibility and simplicity of usability test; and the security test. The findings indicated that online mentoring through professional learn was effective at the highest level.

The purpose of the next reported study, by Kürşat Arslan and Zafer Tanel (Dokuz Eylul University Izmir, Turkey), was to determine IT teacher candidates' attitudes, selfefficacy, and opinions about educational robotic-based programming education: Analyzing the effects of Arduino applications on students' opinions, attitude and selfefficacy in programming class. The study findings showed that using micro-controllers such as Arduino for laboratory applications in programming education had a positive effect on students' attitudes. The study group consisted of undergraduate students who took a $\mathrm{C}$ programming course and traditional teaching as well as weekly Arduino applications that matched with weekly topics. Although students perceived programming education with Arduino as positive, they were careful about this education model in terms of programming knowledge and skill development.

Marwa M. Gaheen (Damietta University, Egypt), Rania M. ElEraky (Damietta University, Egypt and University of Bisha, Saudi Arabia) and Ahmed A. Ewees (Damietta University, Egypt) next present: Automated students Arabic essay scoring using trained neural network by e-Jaya optimization to support personalized system of instruction. A personalized system of instruction is a technique that allows the student to move from one unit to another according to their own pace and potential. In this paper, a proposed method is presented to automatically grade students' Arabic essays to support personalized systems of instruction, using the elitist-Jaya (e-Jaya) optimization algorithm to train the classic artificial neural network (called eJaya-NN). The eJaya-NN outperformed all compared algorithms and achieved the best values.

Beatrice Bonami (University of São Paulo, Brazil and University College London, UK), Selena Nemorin (University College London, UK) then offer: Through three levels of abstraction: Towards an ecological framework for making sense of new technologies in education. This position paper uses an ecological approach to examine how the interface between digital technology and education might be taken up as a complex system with interconnected facets that hold a range of implications. They apply an ecology model to identify the interactions between entities that exist in the hybrid space that intersects human social systems and technical systems, using themes such as knowledge ecology and entropy to analyse how ecology is discussed in extant literature and as a conceptual guide for thinking about how to develop an ecological framework for critical analysis of digital education.

Time to engage: Implementing math and literacy blended learning routines in an Indian elementary classroom is an article by Arnab Kundu (Bankura University, West Bengal, India), Tripti Bej (Srima Balika Vidyalaya, Paschim Medinipore, West Bengal, India) and Mary Rice (University of New Mexico, Albuquerque, USA). The purpose of this study was to investigate the effects of blended environment on students' classroom engagement and to study its potential in unprivileged classrooms. The research involved children from a fourth-grade standard class in an Indian elementary school. The findings revealed that blended learning ambience increases students' classroom engagement in an elementary classroom when teachers are supported with necessary proficiencies. 
Over the past few decades, e-Learning has been implemented to account for the challenges of twenty-first century learning propelled by the internet and use of internetbased technologies say Abdullahi Abubakar Yunusa (Universiti Sains Malaysia, Penang, Malaysia and Usmanu Danfodiyo University Sokoto, Nigeria and Center for Multidisciplinary Research and Innovation, Abuja, Nigeria) and Irfan Naufal Umar (Usmanu Danfodiyo University Sokoto, Nigeria). The following article, A scoping review of Critical Predictive Factors (CPFs) of satisfaction and perceived learning outcomes in E-learning environments describes conduct of a scoping review on predictors of satisfaction and perceived learning to provide an overview of these factors. This included paradigms, research methods, limitations and opportunities for further research. Results from the articles included in their review showed that the DeLone \& McLean Information Systems Success model was the most utilized paradigm in satisfaction and perceived learning studies, while the quantitative research approach is the most deployed research method.

Perceptions of an evidence-based empathy mobile app in post-secondary education describes research by Lisa B. Hoplock, Michelle M. Lobchuk and Jocelyne Lemoine (University of Manitoba, Winnipeg, Canada). They argue that cognitive empathy (also known as perspective-taking) is an important, teachable skill. As part of a knowledge translation project, they identified interest in an evidence-based cognitive empathy mobile app and which faculties believe that cognitive empathy is important for their profession. Results illuminate perceptions of cognitive empathy instruction and technology and also provide insight into issues to consider when developing and implementing an educational communication app.

Teresa López-Pellisa (Universitat de les Illes Balears, Palma de Mallorca, Spain), Neus Rotger (Universitat Oberta de Catalunya, Barcelona, Spain) and Fernando Rodríguez-Gallego (Universitat de les Illes Balears, Palma de Mallorca, Spain) then present: Collaborative writing at work: Peer feedback in a blended learning environment which analyses the nature of peer feedback during a collaborative writing assignment, and identifies possible effects of feedback on the revision of a text written by university students in a blended learning environment. They found that when collaborative writing includes peer feedback, instead of unidirectional corrections from the teacher, the students respond more reflectively and constructively, discussing the content they were working with, and so make significant changes in their own writing.

The final article in this issue: Teachers' skills to integrate technology in education: Two path models explaining instructional and application software use is by Selcuk Dogan and Nihan Agacli Dogan (Georgia Southern University, Statesboro, USA) and Ismail Celik (University of Oulu, Finland). Their study examined the effect of technology support, teachers' confidence in using technology, beliefs about using technology, and perceived skills in the use of instructional and application software. Findings suggest that the most significant factor in teachers' instructional and application software was perceived technology skills, and so professional development for perceived skills or technology competencies of teachers might contribute to the instructional or application software use of teachers. Confidence and comfort in using technology had direct positive effects on instructional and application software.

As usual, this issue contains articles from many researchers around the world. From Argentina, Australia, Austria, Bangladesh, Belgium, Brazil, Bulgaria, Bulgaria, Canada, China, Czech Republic, Denmark, Egypt, Finland, France, Germany, Ghana, 
Greece, Hong Kong, Hungary, India, Indonesia, Iran, Iraq, Ireland, Israel, Liechtenstein, Malaysia, Nigeria, Pakistan, Philippines, Portugal, Russia, Saudi Arabia, Slovak Republic, Sweden, Thailand, The Netherlands, Turkey, UAE, UK, USA and Yemen.

In 2020 we had over 1300 submissions to the journal (288 articles were published in 2020) so this meant a huge effort for our dedicated and professional reviewers. We thank them very much for their efforts.

The COVID-19 pandemic and lock-down had a profound effect on education around the world in 2020 with many schools and universities offering only online teaching for many months. EAIT will soon be publishing a special edition on this topic.

At the end of 2020 we will see the retirement of two very significant members of the journal team: Tony Jones and Bill Davey. Tony and Bill have both been Associate Editors for a good many years, Tony from 2010 to 2019 and Bill from 2010 to 2020. Their tireless work has been of huge benefit to the journal and to my work as Editor-inChief. I am writing now to thank them very much for their efforts in the work of the journal and wish them a happy retirement.

Publisher's note Springer Nature remains neutral with regard to jurisdictional claims in published maps and institutional affiliations. 